\title{
Fibroblast Growth Factor Stimulates Photoreceptor Differentiation in vitro
}

\author{
David Hicks and Yves Courtois \\ INSERM U. 118, 75016 Paris, France
}

Dissociated newborn rat retinal cells were maintained in monolayer culture for periods of up to $11 \mathrm{~d}$. When grown in the absence of exogenous growth factors, $1-2 \%$ of the total neuronal population expressed opsin (the photopigment that is specific for maturing photoreceptors). Addition of a single dose of $10 \mathrm{ng} / \mathrm{ml}$ basic fibroblast growth factor (bFGF) to the culture medium induced an average increase of sixfold in the numbers of neurons expressing opsin. This supplementation had little effect on the total number of differentiated neurons or of glial cells when measured at the same time points. Furthermore, another specific class of retinal neurons, the amacrine cells, showed no changes following exposure to this growth factor. Two other growth factors known to exert neurotrophic effects, epidermal and nerve growth factor, were without effect. The effect of bFGF was dose dependent, with highly significant differences being observed with as little as $100 \mathrm{pg} / \mathrm{ml}$, and with $700 \mathrm{pg} / \mathrm{ml}$ eliciting half-maximal stimulation; maximal effects were observed at $10 \mathrm{ng} / \mathrm{ml}$. Induction of opsin expression by low concentrations of bFGF was blocked completely by an antiserum directed specifically against bFGF, but not by preimmune serum immunoglobulins. This increase in the number of photoreceptors expressing opsin following exposure to bFGF could have been due to either increased cell survival, increased proliferation of progenitor cells, or increased differentiation of immature photoreceptors. There was no increase in overall cell survival under the experimental conditions used, and double labeling immunocytochemistry combined with autoradiographic analysis of ${ }^{3} \mathrm{H}$-thymidine uptake showed that proliferation of neuronal precursors was not enhanced by the addition of bFGF. In contrast to these observations, cultures established from older (postnatal day 3) retina revealed large numbers of opsin-expressing photoreceptors in all culture plates, with or without added growth factors. This reduction in the stimulatory effects of bFGF with increasing postnatal age is consistent with the period of sensitivity being limited to the cycling of neuronal precursors. It is possible that a bFGF-like molecule is secreted by neighboring cells such as the retinal pigmented epithelium, to participate in retinal development and differentiation.

\footnotetext{
Received June 4, 1991; revised Oct. 8, 1991; accepted Dec. 4, 1991.

We thank Dr. M. Vigny for the generous gifts of laminin and anti-bFGF antibody, Dr. H. Prats for the recombinant human bFGF, Dr. P. Brachet for the purified NGF, H. Coët for photographic assistance, and Y. Maville for preparation of the manuscript.

Correspondence should be addressed to David Hicks, Unité de Recherches Gérontologiques, INSERM U. 118, 29 rue Wilhem, 75016 Paris, France.

Copyright (C) 1992 Society for Neuroscience $0270-6474 / 92 / 122022-12 \$ 05.00 / 0$
}

To our understanding, this molecule is the first protein identified to influence specifically the differentiation of photoreceptor cells.

It is becoming increasingly apparent that cellular differentiation within the CNS and retina can be modulated by environmental factors such as the extracellular matrix (ECM) (Adler et al., 1985; Hall et al., 1987), cell adhesion molecules (Rutishauser and Jessell, 1988), and trophic factors (Adler, 1986; Lillien et al., 1990). Certain members of the family of fibroblast growth factors (FGFs) are emerging as strong candidates to play a role in neuronal development, differentiation and function. The prototypes of this gene family are acidic FGF (aFGF) and basic FGF (bFGF), two closely related polypeptides that have potent mitogenic effects on most anchorage-dependent cells (reviewed in Gospodarowicz et al., 1987). Within the CNS, they have been shown to lead to increased neuronal growth and survival both in vivo (Anderson et al., 1988) and in vitro (Walicke et al., 1986). Within the retina, treatment with $\mathrm{aFGF}$ in vilro leads to an elevation in opsin levels (Hicks and Courtois, 1988), and addition of bFGF to newborn retinal cells maintained in defined media leads to a prolongation in cell survival (Hicks et al., 1991). aFGF and bFGF also stimulate outgrowth of retinal ganglion cell processes in vitro (Lipton et al., 1988; Bahr et al., 1989). Also within the retina, both $\mathrm{aFGF}$ and $\mathrm{bFGF}$ and their receptors have been demonstrated: aFGF mRNA (Jacquemin et al., 1990) and protein (Hicks et al., 1991) have been detected in all cellular layers, and at least one class of high-affinity FGF receptor mRN $\Lambda$, the flg-like protein (Lee et al., 1989), is modulated during retinal development (Heuer et al., 1990b). Furthermore, low-affinity FGF binding sites have been demonstrated in ocular basement membranes (Jeanny et al., 1987) and cultured retinal glial cells (Mascarelli et al., 1991), while heparan sulfate proteoglycans, which constitute the low-affinity FGF receptor (Vigny et al., 1988), have been localized within the neural retina and retinal pigmented epithelium (RPE) (Needham et al., 1988; Newsome et al., 1988). High-affinity FGF binding sites, resistant to highmolarity salt extraction and heparitinase digestion, have been demonstrated on retinal cell surfaces (Fayein et al., 1990), photoreceptor outer segments (OS) (Mascarelli et al., 1989), and cultured retinal glial cells (Mascarelli et al., 1991). Even more dramatically, Park and Hollenberg (1989) found that insertion of bFGF-impregnated pellets into retinectomized eyes of embryonic chicks led to the complete regeneration of the neural retina. These authors also found that the RPE had disappeared in treated eyes, suggesting that the regeneration had occurred by transdifferentiation of the RPE into retina, and that curiously the polarity of the newly formed retina was reversed with respect 
to the original (photoreceptors toward the vitreous). Also, intraocular injections of bFGF slow the degeneration of photoreceptor cells in certain inherited retinal diseases (Faktorovich et al., 1990).

Certain other factors, either fully or partially characterized, can influence neuronal metabolism in the CNS and retina. Of course, NGF stimulates outgrowth and survival of cholinergic populations (Mobley et al., 1985). Epidermal growth factor (EGF) has also been reported to stimulate neurite outgrowth in vitro (Morrison et al., 1987, 1988). Brain-derived neurotrophic factor supports the development of retinal ganglion cells as well as other CNS populations (Barde et al., 1987). Transforming growth factor $\beta$ has recently been localized to the photoreceptors by immunochemical techniques (Lutty et al., 1991) and may thus have an important role in photoreceptor function. A partially purified molecule from the retinal interphotoreceptor matrix stimulates photoreceptor survival in vitro (Hewitt et al., 1990), while retinal glial cell-derived factors augment cholinergic activity in vitro (Hofmann, 1988). Hence, it is clear that a number of molecules, either singly or through interactions with the ECM, can influence the fate of neuronal populations.

Relatively little information is available on how growth factors such as bFGF may be involved in the development and differentiation of the CNS. $\Lambda t$ least in the cerebellum the responsiveness of neurons seems to vary with developmental age (Hatten et al., 1988; Morrison et al., 1988). The transcription of flg-like protein varies greatly depending on timing and tissue location, and in the retina seems to be downregulated during the intermediate stages of development (Heuer et al., 1990b). Int-2, another member of the FGF family, is only expressed transiently during development of the CNS (Wilkinson et al., 1989), while aFGF seems to have a later onset and to be maintained throughout life (Caday et al., 1990). Recently, bFGF has been localized to the developing rat retina by immunocytochemical means, and observed to be present in most retinal neurons, with a transient expression by the horizontal cells during the first postnatal week (Connolly et al., 1991). The study described herein was designed to address the question of whether bFGF and other growth factors influence the differentiation of a defined population of neurons, namely, the photoreceptors. We demonstrate that $\mathrm{bFGF}$, but not the other growth factors tested, greatly increases the number of retinal cells that express opsin, while the overall neuronal and glial cell populations remain stable.

\section{Materials and Methods}

Tissue culture. Retinas were isolated from newborn Long-Evans rats within $24 \mathrm{hr}$ after birth (defined as postnatal day 0, PNO), or from 3-dold (PN3) rats, chopped into small fragments, and incubated for 20-30 min at $37^{\circ} \mathrm{C}$ in phosphate-buffered saline (PBS) without $\mathrm{Ca}^{2+}$ or $\mathrm{Mg}^{2+}$, containing $0.1 \mathrm{mg} / \mathrm{ml}$ trypsin (Difco; 1:250) and 0.1 mm EDTA, essentially as described previously (Araki et al., 1987). Enzymatic activity was arrested by the addition of excess Dulbecco's modified Eagle's medium (DMEM) supplemented with 10\% fetal calf serum (FCS), $3 \mathrm{~mm}$ taurine, 2 mM glutamine, and $0.1 \%$ gentamicin and fungizone (DMEM/ $10 \%$ FCS), and gently triturated with narrow-bore Pasteur pipettes to obtain a fully dissociated suspension. Following low-speed centrifugation and washing, cells were examined by inverse-phase optics. Cells were present individually or in small (two or three cells) clusters, and $>95 \%$ remained viable (as ascertained by trypan blue exclusion). They were seeded at $1-1.5 \times 10^{5} / \mathrm{cm}^{2}$ in $0.5 \mathrm{ml} \mathrm{DMEM} / 10 \% \mathrm{FCS}$ into $24-$ well tissue culture plates containing sterilc coverslips precoated with poly-D-lysine (Sigma) $\left(2 \mu \mathrm{g} / \mathrm{cm}^{2}\right.$ in PBS for $15 \mathrm{~min}$ ) followed by laminin $\left(2 \mu \mathrm{g} / \mathrm{cm}^{2}\right.$ in PBS for $1 \mathrm{hr}$ ), and then washed twice in DMEM. Cells were allowed to develop for up to $7 \mathrm{~d}$ with no change of the medium, or for $11 \mathrm{~d}$ with the medium changed after $5 \mathrm{~d}$.

Growth factors and antibodies. Human recombinant bFGF was a generous gift from $H$. Prats (INSERM U. 168). The purified bFGF was stored as a stock solution of $1 \mu \mathrm{g} / \mathrm{ml}$ in growth medium containing $1 \%$ bovine serum albumin (BSA) at $-70^{\circ} \mathrm{C}$. Periodically, aliquots were checked for retention of biological activity by their ability to stimulate ${ }^{3} \mathrm{H}$-thymidine uptake into bovine lens epithelial (BLE) cells (data not shown). EGF (tissue culture grade) was purchased from Collaborative Research Ltd. Purified 7S-NGF was a generous gift from P. Brachet (INSERM U. 298). The anti-bFGF antiserum was raised by immunizing rabbits with recombinant $\mathrm{bFGF}$; serum titers and cross-reactivity were checked by ELISA; the antibodies did not recognize $(<1 \%)$ aFGF. The total immunoglobulin fractions from immune and preimmune sera were purified by ion-exchange chromatography and used at a dilution of $1: 100$. When used at this dilution, the antibody blocked ${ }^{3} \mathrm{H}$-thymidine incorporation into bFGF-stimulated BLE cells (data not shown).

Growth factors (bFGF, 0.1-25 ng/ml; EGF, $20 \mathrm{ng} / \mathrm{ml}$; NGF, $50 \mathrm{ng} /$ $\mathrm{ml}$ in $10 \mu \mathrm{l})$ were added immediately after cell attachment $(\approx 2 \mathrm{hr})$. Anti$\mathrm{bFGF}$ and preimmune IgG were added at the same time as cell seeding. Cultures allowed to develop for $11 \mathrm{~d}$ received an additional aliquot of growth factor at the time of medium change. In one experiment, bFGF $(10 \mathrm{ng} / \mathrm{ml})$ was added every day for $7 \mathrm{~d}$, while in another it was removed after $48 \mathrm{hr}$ and replaced with control growth medium. In another trial, bFGF $(10 \mathrm{ng} / \mathrm{ml})$ was added $72 \mathrm{hr}$ after cell seeding.

Rho-4D2 monoclonal antibody has been previously characterized and binds to the amino terminal of rod photoreceptor opsin (Hicks and Barnstable, 1987; Hicks et al., 1989). Monoclonal antibody HPC-1 labels amacrine cells in developing and adult retina (Barnstable, 1987). Anti-rat neuron-specific enolase (NSE) antiserum is specific for the rat form of NSE and was purchased from Polysciences.

Immunocytochemistry. Immunocytochemistry was performed as described previously (Hicks and Barnstable, 1987). Briefly, coverslips were fixed in 4\% paraformaldehyde in PBS, rinsed, and incubated with PBS containing 1\% BSA (buffer A). They were then incubated in rho-4D2 culture fluid, 1:100, or HPC-1 ascites fluid, 1:400 in buffer A, for 60 $\mathrm{min}$, washed, and labeled with goat anti-mouse/fluorescein isothiocyanate, $10 \mu \mathrm{g} / \mathrm{ml}$ for $60 \mathrm{~min}$ (Biosys). For double labeling, following thorough washing they were permeabilized with $0.1 \%$ Triton $\mathrm{X}-100$, incubated again with buffer $A$, and then incubated successively in NSE antiserum, 1:2000 for $60 \mathrm{~min}$; donkey anti-rabbit $\mathrm{IgG} /$ biotin (Amersham), $10 \mu \mathrm{g} / \mathrm{ml}$ for $60 \mathrm{~min}$; and finally in Extravidin/tetrarhodamine isothiocyanate (Sigma), $10 \mu \mathrm{g} / \mathrm{ml}$ for $60 \mathrm{~min}$. Coverslips were thoroughly washed, mounted, and viewed under a Zeiss photomicroscope equipped with epifluorescence illumination. Additionally, frozen sections of PN3 and PN7 rat retinas, and dissociated cell suspensions from PN0, PN3, and PN7 rat retinas, were processed for anti-NSE and anti-opsin immunocytochemistry.

For quantitative estimates of cell labeling, all rho-4D2 and NSElabeled cells, and flat glial cells observed by phase contrast, were counted within a $1 \mathrm{~mm}^{2}$ ocular grid placed within a $40 \times$ objective. The grid was displaced along a randomly chosen diameter of the coverslip, and a minimum of 1000 NSE-positive cells and 300 rho-4D2-positive cells were counted per coverslip. Each treatment was performed in at least quadruplicate per experiment, and the results presented are from 10 separate experiments.

Combined immunocytochemistry and autoradiography. ${ }^{3} \mathrm{H}$-thymidine ( $1 \mu \mathrm{Ci} / \mathrm{ml}$ ) was added to certain test and control wells for the first 24 $\mathrm{hr}$ of the culture period. Wells were then carefully washed, medium and growth factors replaced, and the cultures allowed to develop for $7 \mathrm{~d}$. Coverslips were then fixed and processed for immunolabeling by rho4D2 and anti-NSE as described above. The coverslips were dehydrated and cemented onto glass slides, dipped in Ilford IL-1 emulsion (Amersham), and stored in light-tight boxes for $2 \mathrm{~d}$ at $4^{\circ} \mathrm{C}$. The slides were then developed in Kodak D-19, fixed, washed, and mounted for microscopic observation. The percentage of labeled (silver grains over nucleus) to unlabeled cells was determined for a minimum of 200-343 randomly selected cells for each treatment (each treatment in duplicate from two separate experiments).

\section{Results}

Culture morphology

Freshly seeded cells were essentially fully dispersed and quickly adhered to the laminin substrate as rounded cells (Fig. 1a). The 

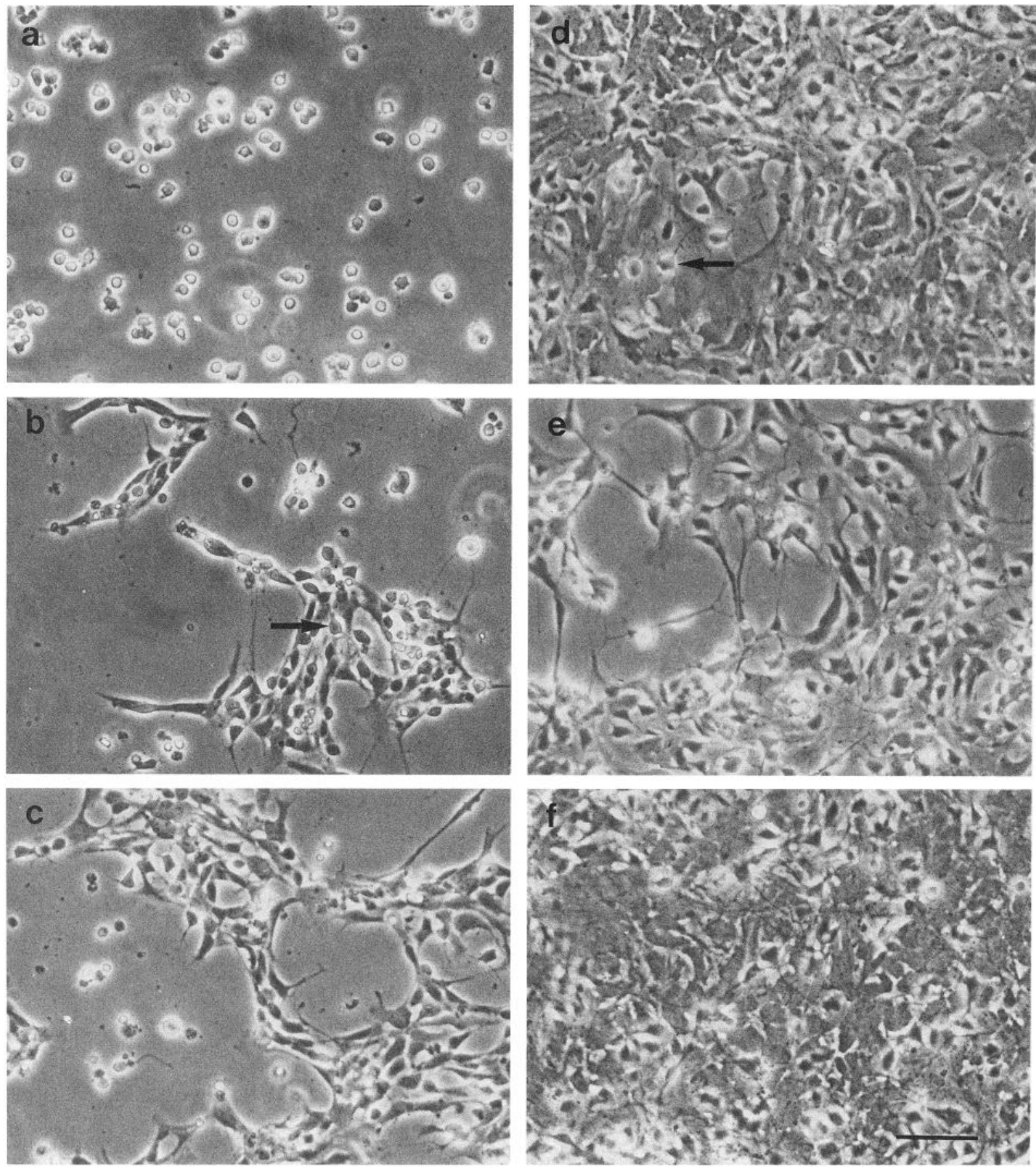

Figure 1. Morphology of newborn rat retinal cultures in the presence or absence of exogenous growth factors. $a$, Three hours after seeding, cells are rounded and mostly present individually. $b$, After $24 \mathrm{hr}$ in untreated cultures, considerable cell spreading has occurred, with islands of glial cells underlying scattered neurons (arrow). $c$, After $24 \mathrm{hr}$ in bFGF- (depicted here) or EGF-treated cultures, cells have already begun to spread and proliferate more rapidly than in control cultures. $d$, By $4 \mathrm{~d}$, cultures receiving bFGF or, in this case, $20 \mathrm{ng} / \mathrm{ml}$ EGF are virtually confluent, with neurons positioned on top of the monolayer (arrow). $e$, Untreated or, in this case, NGF-treated cultures still exhibit some gaps and spaces at $4 \mathrm{~d}$. $f$, After $7 \mathrm{~d}$ in vitro, all cultures are completely confluent, with scattered neurons positioned on top of the underlying glial monolayer. Scale bar, $40 \mu \mathrm{m}$.

retinal glial cells divided rapidly in the serum-supplemented medium, with retinal neurons attached to their surface. By 24 hr, bFGF- and EGF-treated cultures exhibited increased glial spreading compared with untreated or NGF-treated cultures (Fig. $1 b, c$ ). By $4 \mathrm{~d}, \mathrm{FGF}-$ and EGF-containing cultures contained a confluent monolayer of glial cells with the neurons randomly distributed on their surface (Fig. 1d), while control and NGF- treated cultures still contained some gaps (Fig. 1e). However, by $7 \mathrm{~d}$ in vitro, all cultures were confluent (Fig. $1 f$ ).

\section{Immunocytochemistry of retina in vivo}

Examination of frozen sections of PN3 retinas revealed a broad neuroblastic zone (NZ), containing a combination of mature, immature, and migrating cells. Below this layer were the inner 

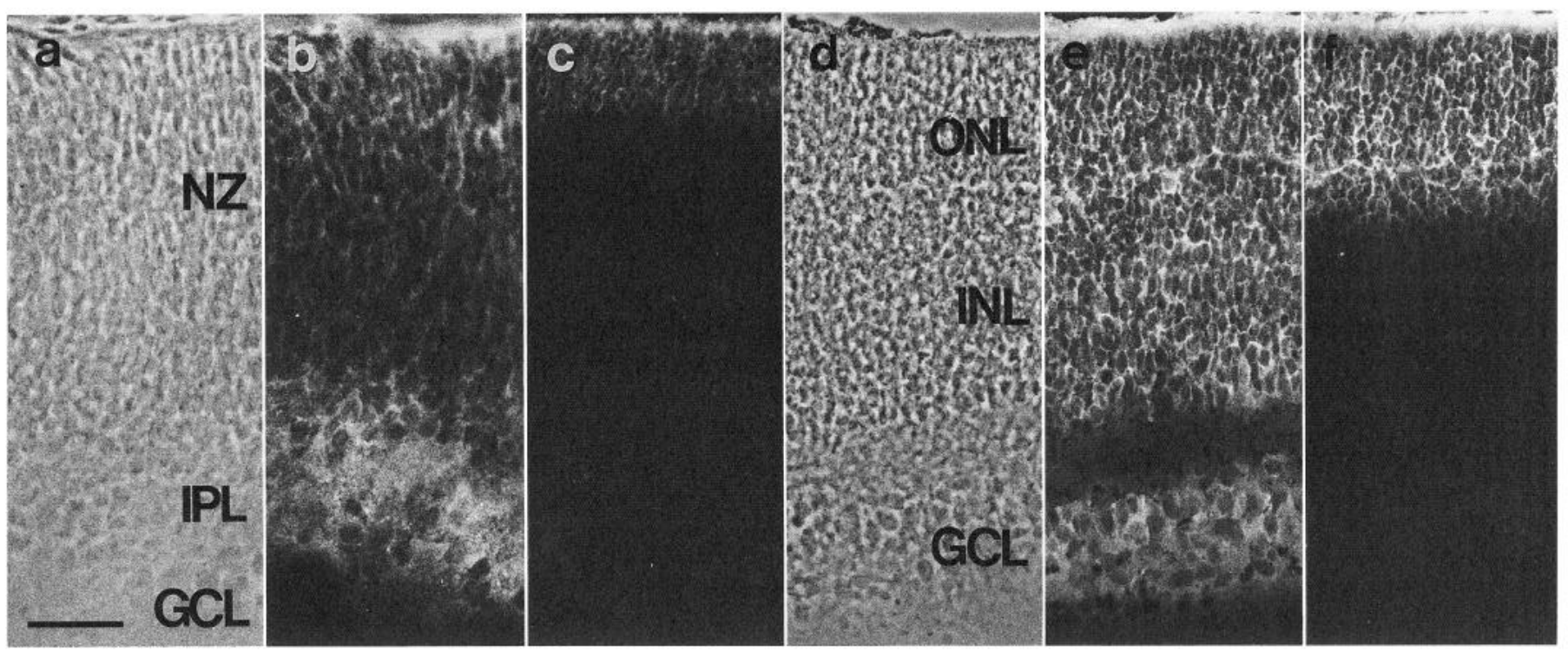

Figure 2. NSE and opsin immunoreactivity in PN3 and PN7 rat retina in vivo: phase-contrast images of PN3 (a) and PN7 $(d)$ retina sections labeled with anti-opsin ( $b$ and $e$ ) and anti-NSE ( $c$ and $f$ ) antibodies, respectively. At PN3, staining for NSE is primarily in the outer $N Z$ and bordering the IPL, while weak opsin immunoreactivity is confined to the scleral border of the NZ. By PN7, NSE immunoreactivity is seen throughout the retina, and opsin expression is intense in the $O N L$. Some opsin immunoreactivity can be seen vitreal to the $O N L$ as well, representing displaced photoreceptor cells. $I N L$, Inner nuclear layer; $G C L$, ganglion cell layer. Scale bar, $25 \mu \mathrm{m}$.

plexiform layer (IPL) and ganglion cell layer (GCL) (Fig. 2a). Staining of such sections with rho-4D2 revealed weak immunolabeling of differentiating photoreceptors aligned along the scleral surface of the NZ (Fig. 2b). Staining of adjacent sections with anti-NSE antibody revealed most intense labeling within differentiating neuronal populations: photoreceptors at the scleral surface of the NZ, and amacrine cells at the vitreal surface of the NZ and within the GCL (Fig. 2c). Cells in the center of the NZ, representing mainly immature, migrating neuroblasts, were only weakly labeled. By PN7, the NZ had split into a scleral half [constituting the outer nuclear layer (ONL), composed exclusively of photoreceptors] and a vitreal half (the inner nuclear layer, containing a number of different neuronal and glial cell types), the two cellular layers being separated by the outer plexiform layer (OPL) (Fig. 2d). Rho-4D2 bound intensely to the ONL [at this age, the majority of photoreceptors have commenced terminal differentiation, with the inner segments(IS), connecting cilia, and rudimentary OS all being formed (Hicks and Barnstable, 1987)] (Fig. 2e). Anti-NSE antiserum labeled all cellular layers (Fig. $2 f$ ). These observations were supplemented by immunolabeling of dissociated retinal cells from these early postnatal ages. Increases were observed in the numbers of both opsin- and NSE-immunoreactive cells. It should be noted that the number of NSE-immunoreactive cells increased roughly linearly throughout this time, whereas the number of opsin-immunoreactive photoreceptors increased mainly in the latter half (days PN4-7) (see Fig. 8, center and bottom panels).

\section{Immunocytochemistry of retina in vitro}

When untreated PN0 cultures were grown for $7 \mathrm{~d}$ (Fig. $3 a$ ) and labeled with anti-NSE antibody, many large multipolar and smaller unipolar neurons were positively labeled (Figs. $3 b, 4 a$ ). Quantitation of such cells revealed an average of $9.9 \times 10^{4} / \mathrm{cm}^{2}$ (Fig. 5). Labeling with rho-4D2 revealed only a few positive cells (Fig. 3c). Irrespective of growth factor treatment, opsincontaining photoreceptors had a small cell-body diameter, a varying number of neurites, and a short vertical process that probably represented the connecting cilium (Fig. $4 b$ ). At this level of resolution, there was no evidence of OS formation. In untreated cultures, these cells accounted for only $1.8 \%$ of the neuronal population, or $1.9 \times 10^{3} / \mathrm{cm}^{2}$ in absolute numbers (Fig. 5). Such cultures also contained $3.6 \times 10^{5}$ glial cells $/ \mathrm{cm}^{2}$. In cultures receiving $10 \mathrm{ng} / \mathrm{ml} \mathrm{bFGF}$ (Fig. $3 d$ ), while the total numbers of NSE-positive $\left(8.8 \times 10^{4} / \mathrm{cm}^{2} ;\right.$ Figs. $\left.3 e, 5\right)$ and glial $(3.9$ $\times 10^{5} / \mathrm{cm}^{2}$ ) cells were not significantly different from untreated values, the numbers of rho-4D2-labeled cells increased to $11.9 \%$ of the neuronal population $\left(10.5 \times 10^{3} / \mathrm{cm}^{2}\right)$, or roughly six times more cells (Figs. 3f, 5). In each of five different experiments, the numbers of opsin-containing cells in bFGF-treated cultures were highly significantly different $(p<0.001)$ from the corresponding untreated controls, such cells in bFGF-treated cultures outnumbering those in untreated controls by three- to eightfold. Addition of bFGF every day for $7 \mathrm{~d}$ did not further increase the number of labeled cells $\left(9.1 \times 10^{3} / \mathrm{cm}^{2}\right)$. Cultures that were washed after $2 \mathrm{~d}$ exposure to $\mathrm{bFGF}$ and maintained in control medium thereafter still showed significant increases in photoreceptor numbers $\left(10.1 \times 10^{3} / \mathrm{cm}^{2}\right)$, whereas in cultures in which bFGF was added after $72 \mathrm{hr}$ the numbers of photoreceptors were not significantly different from untreated controls $\left(2.7 \times 10^{3} / \mathrm{cm}^{2}\right)$.

To see whether this stimulatory effect could be elicited by other growth factors known to exert neurotrophic effects within the CNS, EGF (in most experiments used at $20 \mathrm{ng} / \mathrm{ml}$, but also tested at $0.2,1$, and $5 \mathrm{ng} / \mathrm{ml}$, without any changes) and NGF were tested using the same experimental conditions. Neither factor significantly increased the number of photoreceptors in vitro (EGF, $2.3 \times 10^{3} / \mathrm{cm}^{2}$; NGF, $2.2 \times 10^{3} / \mathrm{cm}^{2}$ ) (Figs. $3 g-l$, 5).

In a separate experiment, the effects of bFGF and EGF on photoreceptors and another specific retinal neuronal population, the amacrine cells, were compared. Whereas bFGF did not influence the number of amacrine cells immunoreactive for HPC-1 


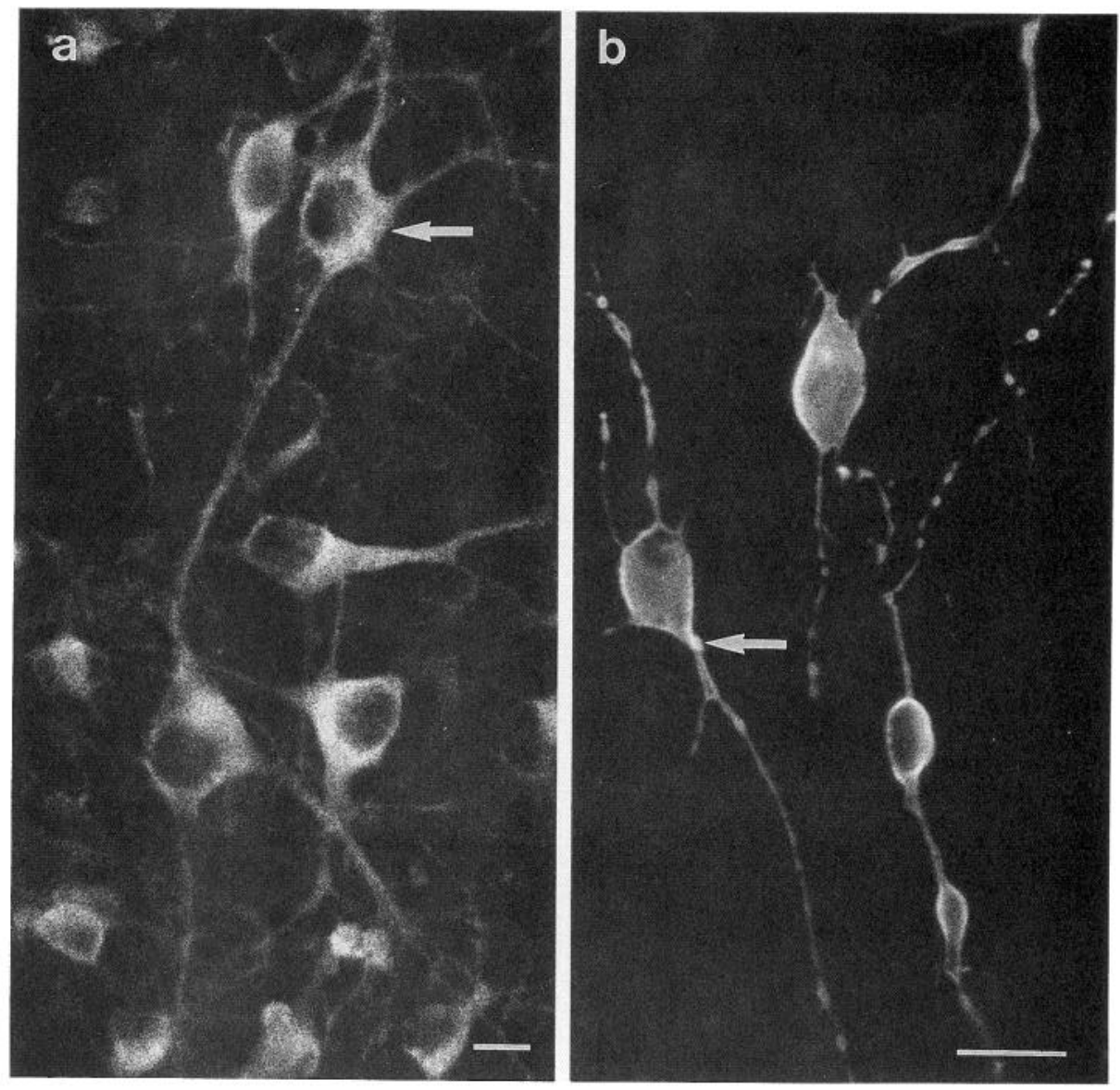

Figure 4. High-power micrographs showing representative retinal cells stained with anti-NSE $(a)$ or anti-opsin (b) antibody. NSE-immunoreactive cells have a range of cell body sizes and are often multipolar ( $a$, arrow). Opsin-immunoreactive photoreceptors are of small diameter and tend to be bipolar, although they can have additional processes. They also possess a connecting cilium, mostly out of the plane of focus in this picture $(b$, arrow $)$. Scale bars, 5 $\mu \mathrm{m}$.

antibody (a marker for amacrine cell differentiation), in parallel cultures the number of opsin-positive cells increased four times relative to untreated controls (Fig. 6). EGF did not influence either population.

The stimulatory effect of bFGF was dose dependent, with highly significant differences observed after a single treatment of $100 \mathrm{pg} / \mathrm{ml} \mathrm{bFGF}$ (opsin-containing cells accounted for $3.8 \pm$ $1.5 \%$ of total neurons). Maximal effects were observed with doses of $10 \mathrm{ng} / \mathrm{ml}$, and the half-maximal dose was $0.7 \mathrm{ng} / \mathrm{ml}$. On the other hand, opsin-expressing cell numbers were not significantly different from control values in cultures treated with $25 \mathrm{ng} / \mathrm{ml}$ bFGF. Numbers of NSE-immunoreactive neurons were unchanged at all concentrations of bFGF. The increase in photoreceptors could be completely blocked at lower doses by the addition of monospecific anti-bFGF IgG, whereas preimmune IgG was without effect (Fig. 7).

In order to examine the developmental maturation of retinal cells in vitro, cultures were also examined at different times from 0 to $8 \mathrm{~d}$. Three main trends were observed. First, glial cell numbers initially rose more rapidly in both bFGF- and EGFtreated cultures than in untreated cultures, although the num- bers in all cultures were similar after $8 \mathrm{~d}$ (Fig. 8, top). Second, the numbers of NSE-immunoreactive neurons also rose more quickly in bFGF- and EGF-treated cultures than in untreated cultures. The numbers of such cells reached a peak at $6 \mathrm{~d}$, after which there appeared to be some cell death. However, in untreated cultures the numbers of NSE-positive neurons rose steadily to reach a plateau at $8 \mathrm{~d}$ (Fig. 8 , center). On the whole, quantitative estimates of the appearance of NSE-immunoreactive neurons $i n$ vitro did not deviate widely from those estimated from age-matched dissociated retina in vivo (Fig. 8, center, broken line). Third, both the numbers and intensity of labeling of opsin-immunoreactive cells remained low in all cultures until $4 \mathrm{~d}$. After this time, there was a small rise in the numbers of such cells in untreated and EGF-treated cultures, and a large increase in bFGF-treated cultures (Fig. 8, bottom). In all cases, there was a large increase in the intensity of immunolabeling for opsin between days 4 and 6 in vitro. Numbers of opsinexpressing cells in dissociated age-matched retina were similarly very low up till PN3, after which they increased rapidly (Fig. 8, bottom, broken line).

Opsin expression in control cultures (untreated, EGF-, or NGF-

Figure 3. Double immunolabeling of retinal cells in vitro showing bFGF enhancement of numbers of opsin-expressing photoreceptors. Newborn rat retinal cells were grown for $7 \mathrm{~d}$ in the absence $(a-c)$ or presence of $10 \mathrm{ng} / \mathrm{ml} \mathrm{bFGF}(d-f), 20 \mathrm{ng} / \mathrm{ml}$ EGF $(g-i)$, or $50 \mathrm{ng} / \mathrm{ml} \mathrm{NGF}(j-l)$. Phasecontrast, low-power images of confluent controls $(a)$, or with bFGF $(d)$, EGF $(g)$ or NGF $(j)$ are shown. NSE antiserum immunoreactivity viewed in same fields: $b$, controls; $e$, bFGF; $h$, EGF; $k$, NGF. Note that the number of labeled cells and pattern of staining are similar in all cases. rho4D2 anti-opsin immunoreactivity in same cells; $c$, controls; $f$, bFGF; $i$, EGF; $l$, NGF. Only in $f$, showing cultures treated with bFGF, are there considerable numbers of positive cells visible. Scale bar, $30 \mu \mathrm{m}$. 

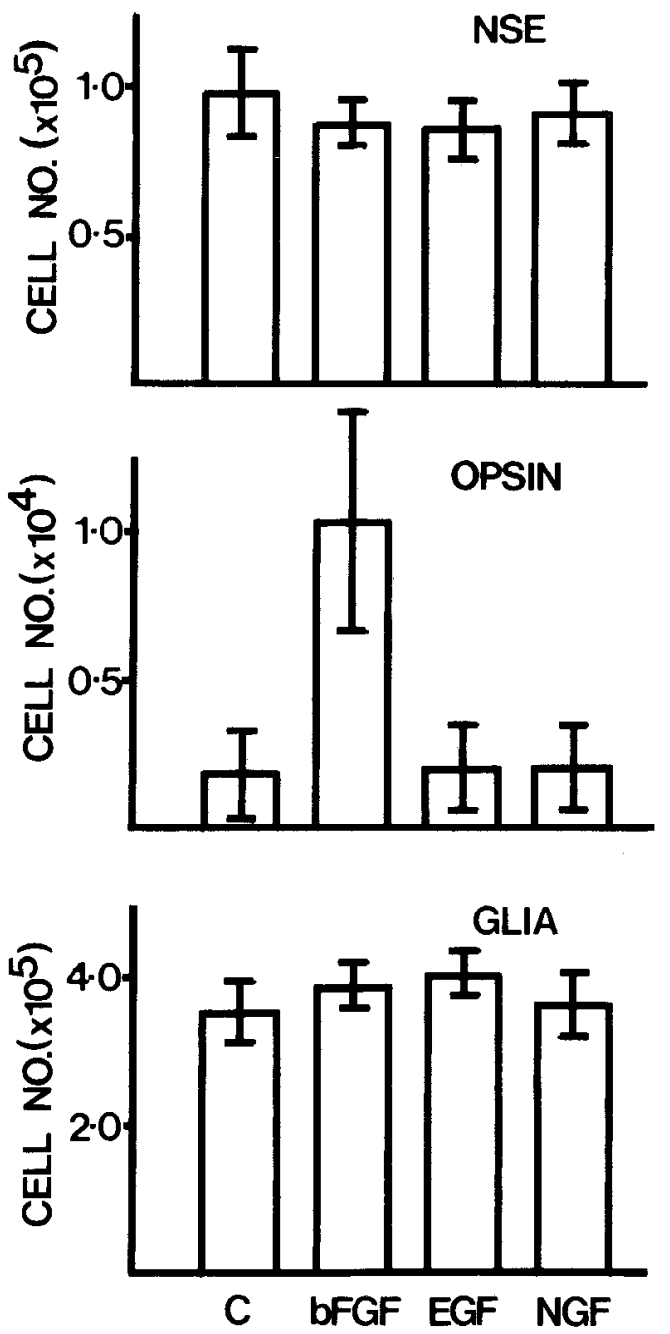

Figure 5. Histograms showing total numbers of NSE-immunoreactive neurons (top), opsin-containing photoreceptors (center), and glial cells (bottom), determined in untreated cultures $(C)$, and in cultures treated with $b F G F, E G F$, or $N G F$, after $7 \mathrm{~d}$. It can be seen that whereas total numbers of neurons and glial cells remain constant, bFGF induces a large rise in ospin-containing cells. Means and SD were gathered from five separate experiments, with a minimum of four coverslips counted per treatment.

treated cultures) does not seem simply to lag behind that in cultures receiving bFGF, as immunolabeling of cells after $11 \mathrm{~d}$ in vitro revealed no significant changes in the numbers of photoreceptors in control cultures $\left(1.9 \times 10^{3} / \mathrm{cm}^{2}\right)$.

Cultures were also established from older rat pups (PN3) and allowed to grow for 5-7 d. As shown in Figure 9, donor age had a large influence on the number of opsin-expressing photoreceptors seen under such conditions. Untreated cultures established from PN3 retina possessed seven times more such cells than did identical cultures established from newborn littermates. Indeed, the numbers of these cells equalled those estimated from dissociated PN7 retina. Whereas bFGF $(10 \mathrm{ng} / \mathrm{ml})$ increased the numbers of opsin-containing cells in the PNO cultures by three times, there was only a slight increase in PN3 cultures after $5 \mathrm{~d}$ in vitro. The photoreceptors observed in the PN3 cultures did not appear to be morphologically different (at the light microscope level) from those seen in PNO cultures. In particular, there was still no evidence of OS formation.

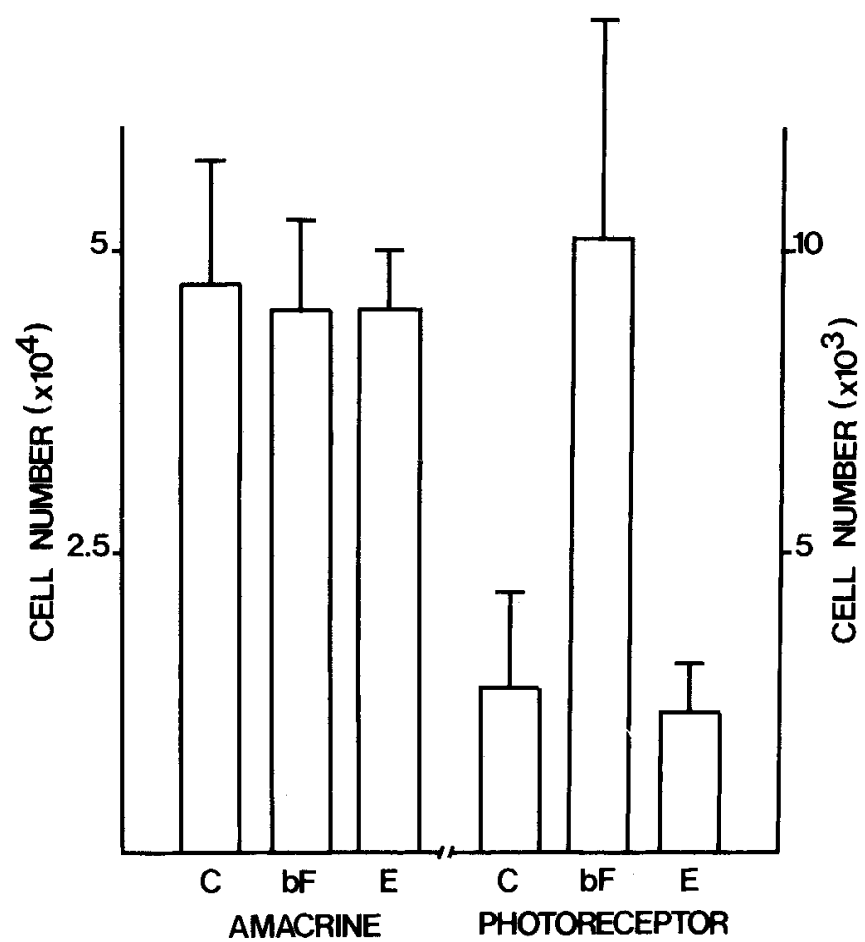

Figure 6. Comparison of numbers of HPC-1-positive amacrine cells and rho-4D2-positive photoreceptors in untreated $(C)$, bFGF-treated $(b F)$, and EGF-treated $(E)$ PN0 retinal cultures after $7 \mathrm{~d}$ in culture. The amacrine cell population remains unchanged, while photoreceptors are four times more numerous following bFGF treatment. Left scale: amacrine cell numbers; right scale: photoreceptor numbers. Means and SD were determined from a single experiment, with two coverslips counted per treatment.

\section{Combined immunocytochemistry/autoradiography}

In wells treated with ${ }^{3} \mathrm{H}$-thymidine, both $\mathrm{bFGF}$ and EGF were shown to stimulate incorporation of the radiolabeled base into glial cells (Table 1). The index of labeled to unlabeled glial cells increased from $47 \%$ in untreated controls to $71 \%$ and $62 \%$ for FGF- and EGF-treated cultures, respectively. In contrast, very low levels of ${ }^{3} \mathrm{H}$-thymidine incorporation into photoreceptors or neurons, irrespective of growth factor addition, were observed (0.5-1\% of total neurons or photoreceptors, for all treatments) (Fig. 10, Table 1).

\section{Discussion}

We have demonstrated that bFGF, but not EGF or NGF, can stimulate the differentiation of immature photoreceptor cells, permitting a much greater number to express the visual pigment opsin without increasing total neuronal numbers. This effect is dose dependent, can be blocked by the use of specific antisera, is not affected by the length of time in culture, and is dependent upon the age of the donor. Furthermore, another specific class of retinal neurons, the amacrine cells, remains unaffected by bFGF.

Much of the process of differentiation, especially that of rod photoreceptor cells, occurs postnatally in the rat retina. Cell birth-dating studies in the mouse retina, in which developmental processes occur slightly earlier than in the rat, have shown that whereas many neuronal populations have stopped dividing by birth (amacrine, horizontal, ganglion, and cone photoreceptor cells), only about $50 \%$ of rod photoreceptors have left the 


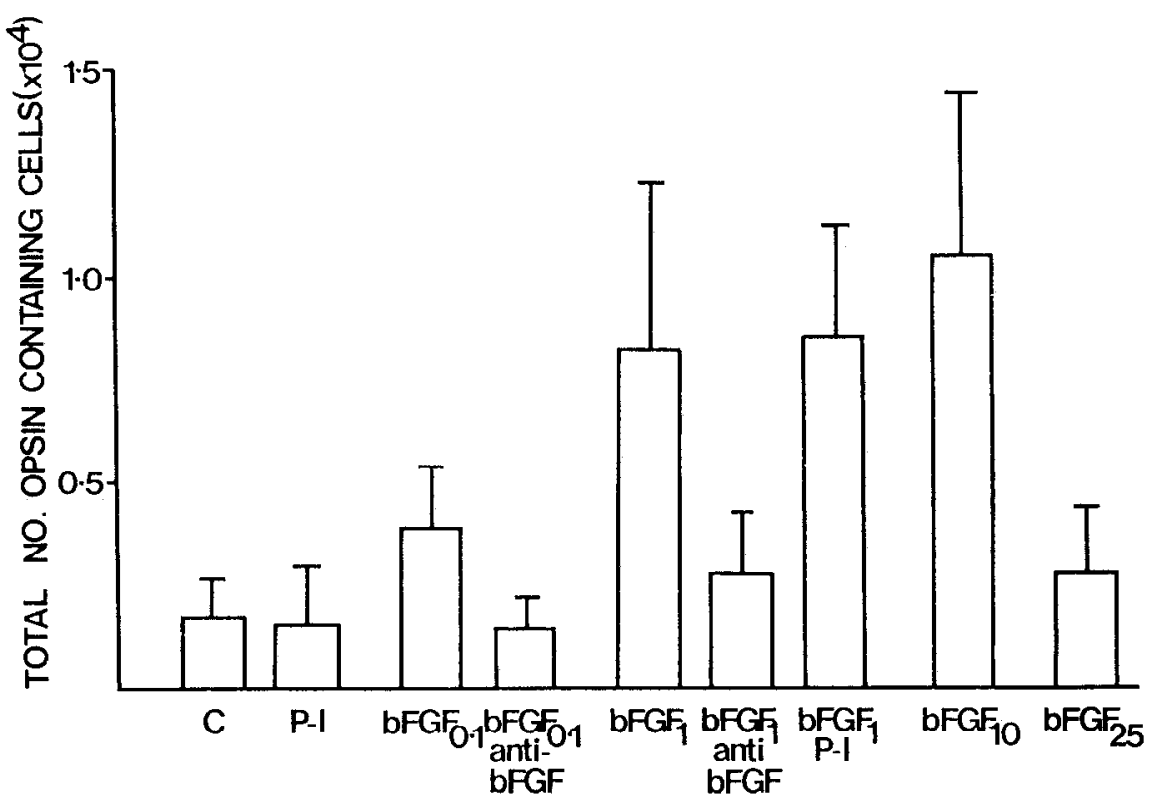

TREATMENT
Figure 7. Dose dependence and antibody blockage of bFGF-induced stimulation of photoreceptor differentiation. PNO cultures received a single administration of $0.1,1,10$, or $25 \mathrm{ng} /$ $\mathrm{ml} b F G F$ and were examined after $7 \mathrm{~d}$. All treatments except the highest dose induced highly significantly different (paired means test, $p \leq 0.005$ ) increases in mature photoreceptors relative to untreated controls $(C)$. Addition of antibFGF IgG $(10 \mu \mathrm{g} / \mathrm{ml})$ completely blocked the effect of bFGF added at 0.1 $\mathrm{ng} / \mathrm{ml}\left(b F G F_{o . l}\right)$ and almost completely $(90 \%)$ blocked the effect of bFGF added at $1 \mathrm{ng} / \mathrm{ml}(b F G F)$. Addition of preimmune IgG $(P-I)$ at the same concentration had no effect. There was no change in the numbers of NSF-positive neurons, irrespective of bFGF concentration or antibody addition. Means and SD were gathered from three separate experiments, with two coverslips examined per treatment. cell cycle (Young, 1985). Several studies have described the postnatal differentiation of rod photoreceptors, with the successive appearance of IS, connecting cilia, and OS (Olney, 1968; Weidman and Kuwabara, 1968). In addition, several studies of opsin cxpression and distribution in developing rods have been reported (Nir et al., 1984; Hicks and Barnstable, 1986; Hicks et al., 1989), showing the movement of opsin into the emerging OS. The rod photoreceptors identified in our cultures using opsin antibody share some of the characteristics of these early in vivo cells: small cell body diameter, possession of a connecting cilium, and a generally bipolar morphology. They also resemble in vivo cells in that opsin synthesis (as observed by antibody binding intensity) increases markedly around PN4-PN5. They clearly differ from their in vivo counterparts in possessing additional subsidiary processes and in not elaborating a recognizable OS (although at the age at which most cells were examined one would not expect substantial OS growth). The cultures also differ in general from the in vivo retina in possessing many more glial cells, which form only a minor population in vivo $(<10 \%$ total cells) but proliferate rapidly in culture to outnumber the total neurons by fivefold. Interestingly, chick photorcceptors seem to be able to differentiate quite extensively in vitro in the absence of contacting cells or added factors (Adler, 1986; Adler and Hatlee, 1989). The photoreceptors in chick cultures are probably mostly cones, and as these cells are born much earlier than rods and exhibit quite different features, they may behave differently from rods with respect to their development in vitro. In the present study, we have been more concerned with quantifying numbers of opsin-containing cells, and have not attempted to examine other parameters such as neurite length and ultrastructural features. Such studies are currently in progress.

The assay depends upon the specificity of the antibody markers used. We would argue that the in vivo labeling patterns and percentages of labeled dissociated retinal cells support the idea that the anti-NSE antiserum is specific for differentiated neurons. The increasing numbers of dissociated retinal cells labeled by rat NSE antiserum during the experimental period $(28 \%$ at $\mathrm{PN} 1,61 \%$ at $\mathrm{PN} 3$, and $91 \%$ at $\mathrm{PN} 7$ ) reflect the increase in the numbers of postmitotic neurons: the majority of cells are unlabeled at PN1, representing the large excess of immature neuroblasts at this age, whereas only $10 \%$ are unlabeled at PN7, representing the remaining neuroblasts and newly differentiating glial cells. From the in vivo labeling pattern, we would argue that photoreceptors are also labeled by this antibody soon after their final mitosis. rho-4D2 is highly specific for rod opsin and does not cross-react with other proteins in the gene family $(\beta$ adrenergic, muscarinic cholinergic, and 5-HT receptors have no sequence homology with rhodopsin in the region of the amino terminal).

The observed increase in the number of photoreceptor cells expressing opsin upon treatment with bFGF could be due to

\begin{tabular}{|c|c|c|c|}
\hline & $\begin{array}{l}7 \text { DIV } \\
\text { PNO C } \\
(n=2)\end{array}$ & $\begin{array}{l}7 \text { DIV } \\
\text { PN0 bFGF } \\
(n=2)\end{array}$ & $\begin{array}{l}7 \text { DIV } \\
\text { PNO EGF } \\
(n=2)\end{array}$ \\
\hline Total glia $(n)$ & 288 & 288 & 343 \\
\hline \multicolumn{4}{|l|}{ Total labeled glia } \\
\hline$n$ & 136 & 207 & 212 \\
\hline$\%$ & $46.5 \pm 14$ & $71.5 \pm 0.5$ & $62.0 \pm 8$ \\
\hline Total neurons ( $n$ ) & 200 & 200 & 200 \\
\hline \multicolumn{4}{|l|}{ Total labeled neurons } \\
\hline$n$ & 2 & 0 & 2 \\
\hline$\%$ & 1 & 0 & 1 \\
\hline Total photoreceptors $(n)$ & 200 & 200 & 200 \\
\hline \multicolumn{4}{|c|}{ Total labeled photoreceptors } \\
\hline$n$ & 1 & 2 & 2 \\
\hline$\%$ & 0.5 & 1 & 1 \\
\hline
\end{tabular}




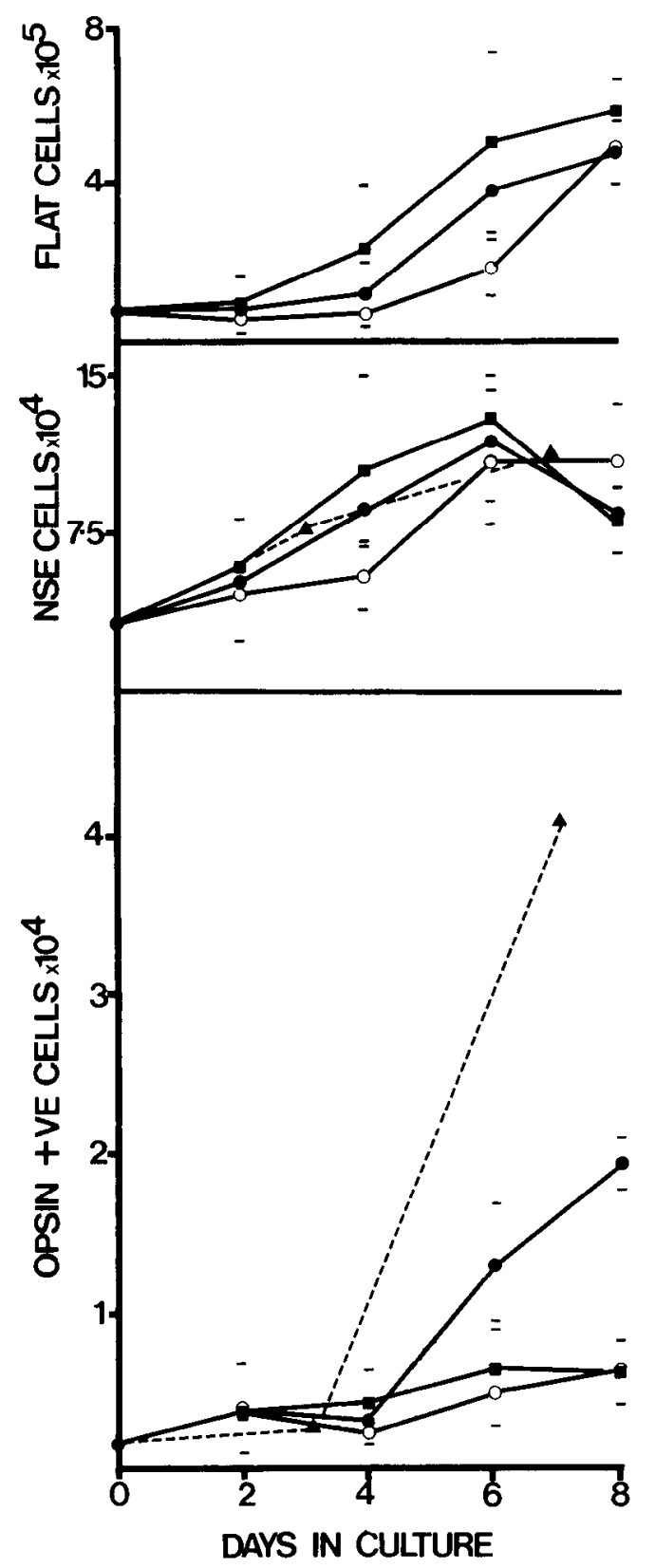

Figure 8. Developmental changes in total flat cells (top), NSE-immunoreactive neurons (center), and opsin-positive photoreceptors (bottom) in vitro. Top, Total flat cells in untreated (open circles), bFGF(solid circles), and EGF-(reated (solid squares) PNO retinal cultures. Center, Total NSE-immunoreactive neurons in similar cultures. Bottom, Total opsin-positive cells in PN0 cultures; symbols as above. In the center and bottom panels, the estimated numbers of NSE- and opsinpositive cells from dissociated PN0, PN3, and PN7 retinas have been plotted to the same scale (solid triangles and broken lines). For an explanation of the graphs, see Results. Means and SD were determined from two separate experiments, with two coverslips counted per data point.

several phenomena: increased cell survival, incrcased differentiation, or increased proliferation. Addition of bFGF does not increase the total neuronal numbers; although there appears to be some increase in NSE-immunoreactive neurons in bFGFand EGF-treated cultures up to $6 \mathrm{~d}$ in vitro, levels are similar between these and control cultures at later times and resemble the values estimated from dissociated PN1-PN7 retinas. Nei-

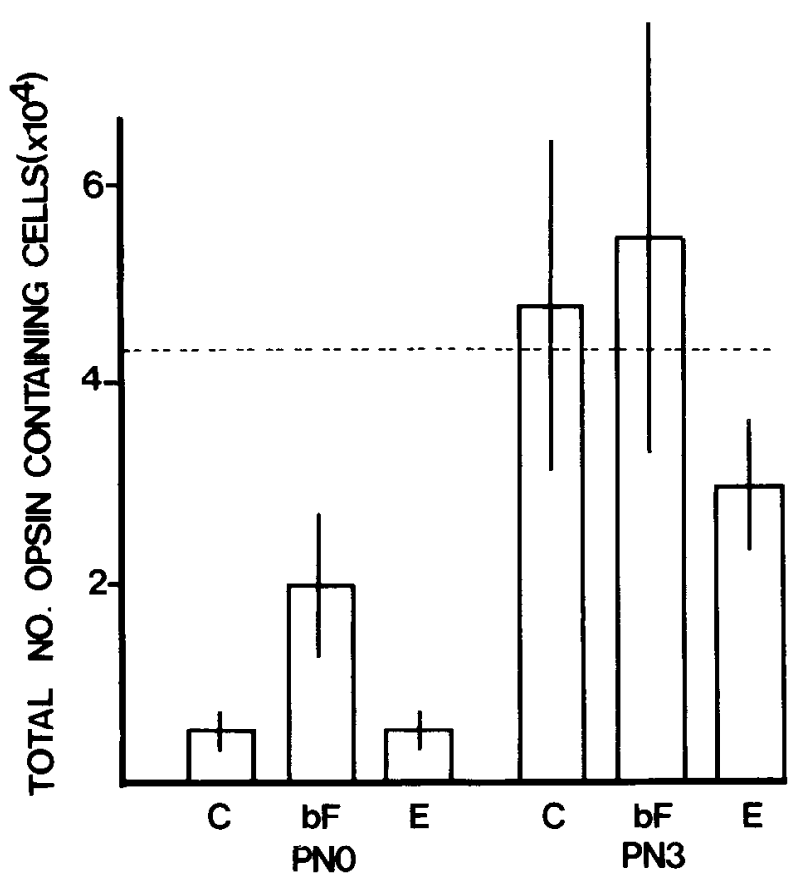

Figure 9. Opsin-containing cell numbers in $\mathrm{PNO}$ and $\mathrm{PN} 3$ retinal cultures. $P N O$ retina were grown for $7 \mathrm{~d}$ in the absence $(C)$ or presence of bFGF $(10 \mathrm{ng} / \mathrm{ml})(b F)$ or EGF $(20 \mathrm{ng} / \mathrm{ml})(E) ; P N 3$ cultures were grown for $5 \mathrm{~d}$ under identical conditions. Seven times more photoreceptors were counted in untreated PN3 than in untreated PN0 cultures. bFGF increased such cell numbers by $300 \%$ relative to untreated controls in PNO, but only by $14 \%$ in PN3 cultures. The broken line represents the numbers of photoreceptors present in dissociated PN7 retina, drawn to the same scale. Means and SD were determined from two separate experiments, with three coverslips counted for each treatment.

ther are there changes in the numbers of another specific population, the amacrine cells. So there is no stimulation of general neuronal survival. There is very little incorporation of ${ }^{3} \mathrm{H}$-thymidine by any nonglial cells in vitro, either with or without exogenous factors, so the increase is not due to enhanced proliferation of progenitor cells. Given these data, the most likely explanation is that bFGF permits continued differentiation toward the mature phenotype under conditions in which it is otherwise severely restricted. For example, opsin synthesis itself may be stimulated by bFGF, with the majority of untreated cells not generating detectable levels of this protein. Although we have not examined aFGF in the present study, we showed previously that this factor too led to increased opsin levels in retinal cultures, as determined by radioimmunoassay (Hicks and Courtois, 1988). In this previous study, the culture conditions were different from those used here, and we were unable to demonstrate whether this increase was due to increased cell numbers or increased synthesis per cell.

The timing of the phenomenon seems to be very important. Whereas newborn rat retinal cells are strongly influenced, cultures established from PN3 rat retinas appear rather refractory to $\mathrm{bFGF}$, and the numbers of opsin-expressing photoreceptors after $5 \mathrm{~d}$ in vitro equal those determined from age-matched (PN7) in vivo retinas. Furthermore, the increase is seen even when bFGF is removed after $2 \mathrm{~d}$, but is not seen when the factor is added after the third day. In addition, the increase in the numbers of opsin-containing cells with increasing postnatal age observed in vivo and in bFGF-treated cultures does not seem 



Figure 10. Glial, neuronal, and photoreceptor cell division in vitro. PN0 retinal cultures were incubated with ${ }^{3} \mathrm{H}$-thymidine during the first $24 \mathrm{hr}$ in culture, after which fresh medium was added. Growth factors were added for the entire culture period. Cultures were fixed after $7 \mathrm{~d}$ and processed for immunocytochemistry and autoradiography. This figure shows an untreated culture. $a$, Phase-contrast image showing silver grains overlying flattened glial cells (long arrows), but not birefringent neurons (short arrows) or photoreceptors (arrowhead). $b$, Staining of same field with antiNSE antibodies. $c$, Staining of same field with rho-4D2 anti-opsin antibody. No label was incorporated into either total neurons or photoreceptors in these fields. bFGF- and EGF-treated cultures did not differ from untreated controls with regard to neurons or photoreceptors, but incorporation of the label into glial cells was markedly increased. Scale bar, $10 \mu \mathrm{m}$.

to be linear, but rather increases dramatically after $3-4 \mathrm{~d}$. This is again suggestive of some kind of inductive event, whereby the cells are "primed" during this period. In a more general sense, one can speculate that the "specificity" of the effects of bFGF may be determined by the position of retinal cells within the cell cycle at the time of treatment. Using newborn rat retina in which the major neuronal type remaining to be born is the rod photoreceptor (Young, 1985) may thus limit bFGF action to this type, and populations such as the amacrine cells, which are already differentiating, are no longer sensitive. As we have not examined embryonic retina, it is possible that bFGF may have even more dramatic effects at earlier developmental stages.

We cannot exclude the possiblity that bFGF stimulates photoreceptor differentiation indirectly, either by interacting with other growth factors that may be present in the serum supplemented medium or, for example, by stimulating the underlying retinal glial monolayer to synthesize some other molecule important in photoreceptor maturation. In vitro evidence suggests that Müller cell-photoreceptor interactions are important in modulating both phenotypes (Linser and Moscona, 1983; Grosse et al., 1986). Also, in vivo evidence suggests that loss of photoreceptor cells leads to secondary alterations in the Müller cell phenotype (Eisenfeld et al., 1984). Glial cells in vitro respond mitotically to exogenous bFGF (Mascarelli et al., 1991) and modulate their synthesis of specific proteins in response to FGF (Morrison et al., 1985). Additionally, Müller cells synthesize ECM components such as laminin (Wakakura and Foulds, 1989), which are important in retinal metabolism (Adler, 1986).

However, the effect is still specific for bFGF in that EGF, also highly mitogenic for glial cells (Huff et al., 1990), has no effect on the numbers of opsin-containing photoreceptors. NGF, which is neurotrophic for cholinergic CNS neurons (Mobley et al., 1985), is synthesized by retinal Müller cells in vivo (Chakrabarti et al., 1990), and whose receptor is developmentally regulated in the retina (Heuer et al., 1990a), does not increase photoreceptor numbers. On the other hand, it has been clearly shown that bFGF can directly influence neuronal behavior in the absence of glial cells (Walicke and Baird, 1988).

If $b F G F$ does in fact play a role in retinal, especially photoreceptor, cell biology, what are the possible in vivo sources and mode of action? FGF mRNA has been detected in RPE from species such as cow (Schweigerer et al., 1987) and rat (Hicks et al., 1991). aFGF mRNA is present throughout the neural retina (Jacquemin et al., 1990; Noji et al., 1990), while bFGF mRNA only appears to be present in photoreceptors (Noji et al., 1990). Additionally, RPE cells (Plouët et al., 1988) and 
neural retina (Fayein et al., 1990; Heuer et al., 1990b) possess high-affinity cell surface FGF receptors. High levels of bFGF have been observed in the interphotoreceptor matrix (IPM; Kirchoff-Rempe et al., 1991; Hageman et al., in press), despite the observation that bFGF lacks any signal sequence or cellular distribution suggesting a secretory protein (Renko et al., 1990). The presence of bFGF in the IPM may contribute to the photoreceptor survival-stimulating activity observed in this latter by Hewitt et al. (1990), as their partially purified preparation exhibited certain FGF-like features (affinity for heparin). However, the molecule they described was of higher molecular weight and displayed weaker binding affinities than either aFGF or bFGF, and may represent another member of the heparin-binding growth factor family. As the RPE appears to differentiate prior to the retina (Barnstable, 1987), it may release bFGF into the IPM to interact with binding sites present at the scleral surface of the NZ. Significantly, transplantation of normal RPE into the Royal College of Surgeons (RCS) rat, which displays inherited retinal degeneration (Mullen and La Vail, 1976), permits survival of photoreceptors otherwise destined to die ( $\mathrm{Li}$ and Turner, 1988). This rescue effect may be due to diffusible trophic factors, and the effect can be mimicked by intraocular injection of bFGF (Faktorovich et al., 1990). Hence, the RPE, in addition to its other functions (reviewed in Bok, 1985), may provide bFGF. Of course bFGF is unlikely to be acting alone, and it is possible that other growth factors may be acting either independently or in synergy with bFGF. As aFGF has a similar retinal distribution to bFGF (Connolly et al., 1991; Hicks et al., 1991), and in many cases binds to the same FGF receptors as bFGF (Bernard et al., 1991), this molecule too may be involved.

In conclusion, we have demonstrated that bFGF stimulates photoreceptor differentiation, and that other neurotrophic growth factors, such as EGF and NGF, have no effect, despite being mitogenic for glial cells and bearing certain resemblances to FGF in their second messenger systems. We are currently investigating whether the stimulatory effect is direct or via the adjacent Müller cells. bFGF seems well placed to be one of the key factors that affect neuronal differentiation.

\section{References}

Adler R (1986) Trophic interactions in retinal development and in retinal degenerations. In vivo and in vitro studies. In: The retina: a model for cell biology studies (Adler R, Farber D, eds), pp 111-148. New York: Academic.

Adler R, Hatlee M (1989) Plasticity and differentiation of embryonic retinal cells at terminal mitosis. Science 243:391-393.

Adler R, Jerdan J, Hewitt A (1985) Responses of cultured neural retinal cells to substratum-bound laminin and other extracellular matrix molecules. Dev Biol 112:100-114.

Anderson K, Dam D, Lee S, Cotman C (1988) Basic fibroblast growth factor prevents death of lesioned cholinergic neurons in vivo. Nature 332:360-361.

Araki M, Iida Y, Taketani S, Watanabe K, Ohta T, Saito T (1987) Characterization of photoreceptor cell differentiation in the rat retinal cell culture. Dev Biol 124:239-247.

Bahr M, Vanselow J, Thanos S (1989) Ability of adult rat ganglion cells to regrow axons in vitro can be influenced by fibroblast growth factor and gangliosides. Neurosci Lett 96:197-201.

Barde Y, Davies A, Johnson J, Lindsay R, Thoenen H (1987) Brain derived neurotrophic factor. Prog Brain Res 71:185-189.

Barnstable C (1987) A molecular view of vertebrate retinal development. Mol Neurobiol 1:9-46.

Bernard O, Li M, Reid H (1991) Expression of two different forms of fibroblast growth factor receptor 1 in different mouse tissues and cell lines. Proc Natl Acad Sci USA 88:7625-7629.
Bok D (1985) Retinal photoreceptor-pigment epithelium interactions. Invest Ophthalmol Vis Sci 26:1659-1694.

Caday C, Klagsbrun M, Fanning P, Mirzabegian A, Finklestein S (1990) Fibroblast growth factor (FGF) levels in the developing rat brain. Dev Brain Res 52:241-246.

Chakrabarti S, Sima A, Lee J, Brachet P, Dicou E (1990) Nerve growth factor (NGF), proNGF and NGF receptor-like immunoreactivity in BB rat retina. Brain Res 523:11-15.

Connolly S, Hjelmeland L, LaVail M (1991) Localization of bFGF in developing retinas of normal and RCS rats. Invest Ophthalmol Vis Sci [Suppl] 32:754.

Eisenfeld A, Bunt-Milam A, Sarthy P (1984) Müller cell expression of glial fibrillary acidic protein after genetic and experimental photoreceptor degeneration in the rat retina. Invest Ophthalmol Vis Sci 25:1321-1328.

Faktorovich E, Steinberg R, Yasumura D, Matthes M, La Vail M (1990) Photoreceptor degeneration in inherited retinal dystrophy delayed by basic fibroblast growth factor. Nature 347:83-86.

Fayein N, Courtois Y, Jeanny U (1990) Ontogeny of basic fibroblast growth factor binding sites in mouse ocular tissues. Exp Cell Res 188: $75-88$.

Gospodarowicz D, Ferrara N, Schweigerer L, Neufeld G (1987) Structural characteristics and biological functions of fibroblast growth factor. Endocrine Rev 8:95-114.

Grosse G, Wenzel M, Lindner G (1986) Raster elektronen mikroskopische und lichtmikroskopische Untersuchungen der Retina von Hühnerrembroyonen in Zellkultwen. J Hirnforsch 27:587-596.

Hageman G, Kirchoff-Rempe M, Lewis G, Fisher S, Anderson D (1991) Sequestration of hasic fibroblast growth factor in the primate retinal interphotoreceptor matrix. Proc Natl Acad Sci USA 88:6706-6710.

Hall D, Neugebauer K, Reichardt L (1987) Embryonic neural retinal cell response to extracellular matrix proteins: developmental changes and effects of the cell substratum attachment antibody (CSAT). J Cell Biol 104:623-634.

Hatten M, Lynch M, Rydel R, Sanchę J, Joseph-Silverstein J, Moscatelli D, Rifkin D (1988) In vitro neurite extension by granule neurons is dependent upon astroglial-derived fibroblast growth factor. Dev Biol 125:280-289.

Heuer J, Fatemie-Nainie S, Wheeler E, Bothwell M (1990a) Structure and developmental expression of the chicken NGF receptor. Dev Biol $137: 287-304$

Heuer J, Von Bartheld C, Kinoshita Y, Evers P, Bothwell M (1990b) Alternating phases of FGF receptor and NGF receptor expression in the developing chicken nervous system. Neuron 5:283-296.

Hewitt A, Lindsey J, Carbott D, Adler R (1990) Photoreceptor survival-promoting activity in interphotoreceptor matrix preparations: characterization and partial purification. Exp Eye Res 50:79-88.

Hicks D, Barnstable C (1986) Lectin and antibody labelling of developing rat photoreceptor cells: an electron microscope immunocytochemical study. J Neurocytol 15:219-230.

Hicks D, Barnstable C (1987) Different rhodopsin monoclonal antibodies reveal different binding patterns on developing and adult rat retina. J Histochem Cytochem 35:1317-1328.

Hicks D, Courtois Y (1988) Acidic fibroblast growth factor stimulates opsin levels in retinal photoreceptor cells in vitro. FEBS Lett 234: $475-479$.

Hicks D, Sparrow J, Barnstahle C (1989) Immunoelectron microscopical examination of the surface distribution of opsin in rat rod photoreceptor cells. Exp Eye Res 49:13-29.

Hicks D, Bugra K, Faucheux B, Jeanny J, Laurent M, Malecaze F, Mascarelli F, Raulais D, Cohen Y, Courtois Y (1991) Fibroblast growth factors in the retina. In: Progress in retinal research (Osborne $\mathrm{N}$, Chader G, eds), vol 11, pp 333-374. Oxford: Pergamon.

Hofmann H (1988) Development of cholinergic retinal neurons from embryonic chicken in monolayer cultures: stimulation by glial cell derived factors. J Neurosci 8:1361-1369.

Huff K, Schreier W, Luminita I (1990) Proliferation-related responses in rat astrocytes to epidermal growth factor. Int $J$ Dev Neurosci 8: 255-266.

Jacquemin E, Halley C, Alterio J, Laurent M, Courtois Y, Jeanny J (1990) Localization of acidic fibroblast growth factor (aFGF) mRNA in mouse and bovine retina by in situ hybridization. Neurosci Lett 116:23-28.

Jeanny J, Fayein N, Moenner M, Chevallier B, Barritault D, Courtois $Y$ (1987) Specific fixation of bovine brain and retinal acidic and 
basic fibroblast growth factors to mouse embryonic eye basement membranes. Exp Cell Res 171:63-75.

Kirchoff-Rempe M, Hageman G, Lewis G, Fisher S, Anderson K, Anderson D (1991) Association of immunoreactive basic fibroblast growth factor with the insoluble interphotoreceptor matrix. Invest Ophthalmol Vis Sci [Suppl] 32:1216.

Lee P, Johnson D, Cousens L, Fried V, Williams L (1989) Purification and complementary DNA cloning of a receptor for basic fibroblast growth factor. Science 245:57-60.

Li L, Turner J (1988) Inherited retinal dystrophy in the RCS rat: prevention of photoreceptor degeneration by pigment epithelial cell transplantation. Exp Eye Res 47:911-917.

Lillien L, Sendtner M, Raff M (1990) Extracellular matrix-associated molecules collaborate with ciliary neurotrophic factor to induce type 2 astrocyte development. J Cell Biol 111:635-644.

Linser P, Moscona A (1983) Hormonal induction of glutamine synthetase in cultures of embryonic retina cells: requirement for neuronglia contact interactions. Dev Biol 96:529-534.

Lipton S, Wagner J, Madison R, D'Amore P (1988) Acidic fibroblast growth factor enhances regeneration of processes by postnatal mammalian retinal ganglion cells in culture. Proc Natl Acad Sci USA 85 : $2388-2392$.

Lutty G, Ikeda K, Chandler C, McLeod D (1991) Immunohistochemical localization of transforming growth factor beta in human photoreceptors. Curr Eye Res 10:61-73.

Mascarelli F, Raulais D, Courtois Y (1989) Fibroblast growth factor phosphorylation and receptors in rod outer segments. EMBO J 8: 2265-2273.

Mascarelli F, Tassin J, Courtois Y (1991) Fffects of FGF's on adult bovine Müller cells: proliferation, binding and internalization. Growth Factors 4:81-95.

Mobley W, Rutkowski J, Tennekoon G, Buchanan K, Johnston M (1985) Choline acetyltransferase activity in striatum of neonatal rats increased by nerve growth factor. Science 229:284-287.

Morrison R, De Vellis J, Lee Y, Bradshaw R, Eng L (1985) Hormones and growth factors induce the synthesis of glial fibrillary acidic protein in rat brain astrocytes. J Neurosci Res 14:167-176.

Morrison R, Kornblum H, Leslie F, Bradshaw R (1987) Trophic stimulation of cultured neurons from neonatal rat brain by epidermal growth factor. Science 238:72-75.

Morrison R, Keating R, Moskal J (1988) Basic fibroblast growth factor and epidermal growth factor exert differential trophic effects on CNS neurons. J Neurosci Res 21:71-79.

Mullen R, LaVail M (1976) Inherited retinal dystrophy: primary defect in pigment epithelium cells determined with experimental rat chimeras. Science 192:799-801.

Needham L, Adler R, Hewitt A (1988) Proteoglycan synthesis in flat cell-free cultures of chick embryo retinal neurons and photoreceptors. Dev Biol 126:304-314.
Newsome D, Pfeffer B, Hewitt A, Robey P, Hassell J (1988) Detection of extracellular matrix molecules synthesized in vitro by monkey and human retinal pigmented epithelium: influence of donor age and multiple passages. Exp Eye Res 46:305-321.

Nir I, Cohen D, Papermaster D (1984) Immunocytochemical localization of opsin in the cell membrane of developing rat photoreceptors. J Cell Biol 98:1788-1795.

Noji S, Matsuo T, Koyama E, Yamaai T, Nohno T, Matsuo N, Taniguchi S (1990) Expression pattern of acidic and basic fibroblast growth factor genes in adult rat eyes. Biochem Biophys Res Commun 168:343-349.

Olney J (1968) An electron microscopic study of synapse formation, receptor outer segment development, and other aspects of developing mouse retina. Invest Ophthalmol 7:250-268.

Park C, Hollenberg M (1989). Basic fibroblast growth factor induces retinal regeneration in vivo. Dev Biol 134:201-205.

Plouët J, Mascarelli F, Loret M, Faure J, Courtois Y (1988) Regulation of eye derived growth factor binding to membranes by light, ATP or GTP in photoreceptor outer segments. EMBO J 7:373-376.

Renko M, Quarto N, Morimoto T, Rifkin D (1990) Nuclear and cytoplasmic localization of different basic fibroblast growth factor species. J Cell Physiol 144:108-114.

Rutishauser U, Jessell T (1988) Cell adhesion molecules in vertebrate neural development. Physiol Rev 68:819-857.

Schweigerer L, Malerstein B, Neufeld G, Gospodarowicz D (1987) Basic fibroblast growth factor is synthesized in cultured retinal pigment epithelial cells. Biochem Biophys Res Commun 143:934-940.

Vigny M, Ollier-Hartmann M, Lavigne M, Fayein N, Jeanny J, Laurent M, Courtois Y (1988) Specific binding of basic fibroblast growth factor to basement membrane-like structures and to purified heparan sulfate proteoglycan of the EHS tumor. J Cell Physiol 137:321-328.

Wakakura M, Foulds W (1989) Laminin expressed by cultured Muller cells stimulates growth of retinal neurites. Exp Eye Res 48:577-582.

Walicke P, Baird A (1988) Neurotrophic effects of basic and acidic fibroblast growth factors are not mediated through glial cells. Dev Brain Res 40:71-79.

Walicke P, Cowan W, Ueno N, Baird A, Guillemein R (1986) Fibroblast growth factor promotes survival of dissociated hippocampal neurons and enhances neurite extension. Proc Natl Acad Sci USA 83:3012-3016.

Weidman T, Kuwabara T (1968) Postnatal development of the rat retina: an electron microscopic study. Arch Ophthalmol (Copenh) 79: $470-484$.

Wilkinson D, Bhatt S, McMahon A (1989) Expression pattern of the FGF-related proto-oncogene int-2 suggests multiple roles in fetal development. Development 105:131-136.

Young R (1985) Cell differentiation in the retina of the mouse. Anat Rec 212:199-205. 